\title{
Spreading Depression Following Experimental Head Injury in the Rat
}

\author{
Kenro Sunami, Takao NaKamura, Motoo Kubota, Yoshinori Ozawa, \\ Hiroki NAMBA, Akira YAMAURA and Hiroyasu MAKINO
}

Department of Neurological Surgery, School of Medicine, Chiba University, Chiba

\begin{abstract}
The direct current (DC) potential and electroencephalographic (EEG) changes were continuously monitored following fluid percussion head injury (brain contusion) in 10 conscious rats. Local cerebral glucose utilization (LCGU) was measured by the autoradiographic $\left[{ }^{14} \mathrm{C}\right]$ deoxyglucose method. Measurement of LCGU was started at the lowest point of the first or second DC potential negative shift when it occurred, and 2 hours after contusion if no DC potential changes were observed. The DC potential did not change in four rats (Group A), whereas DC potential negative shifts together with marked suppression of EEG activity occurred at $54 \pm 6.9$ minutes after injury in six rats (Group B). In Group A, LCGU was decreased nonsignificantly in both the right and left cortices. In Group B, however, LCGU in the lesioned cortex rose to $160-190 \%$ of the level observed in the contralateral cortex $(p<0.05)$. The autoradiographic pattern in Group B was identical to that seen in spreading depression. These findings can contribute to the effort to better understand the pathophysiology of head injury.
\end{abstract}

Key words: head injuries, cerebral metaholism, spreading depression, deoxyglucose, brain contusion

\section{Introduction}

Following brain concussion, a brief increase in glucose metabolism has been observed in some parts of the cerebral hemispheres ${ }^{30,31,34)}$ and the brainstem. ${ }^{12)}$ After severe head injury, the cerebral oxygen metabolic rate is believed to be consistently depressed, ${ }^{1,2,25,33)}$ but local cerebral metabolic changes have not been clearly identified. Using the $\left[{ }^{14} \mathrm{C}\right]$ deoxyglucose method, Nakamura et al. ${ }^{28)}$ found hypermetabolic changes in the cortex and hippocampus of rats 2 hours after mechanical brain injury. They suggested spreading depression (SD) as a possible mechanism, but the delayed occurrence of SD following head injury has not yet been verified. Measurement of the direct current (DC) potential along with electroencephalographic (EEG) recording are essential to document the occurrence of SD. ${ }^{22,23)} \mathrm{We}$ studied local cerebral glucose utilization (LCGU) in rats following brain contusion, using the $\left[{ }^{14} \mathrm{C}\right]$ deoxyglucose method (Sokoloff et al., 1977) ${ }^{37)}$ combined with EEG and DC potential recordings. We then

\footnotetext{
Received November 7, 1988; Accepted July 4, 1989
}

compared these quantitative data with the wellknown EEG features of SD.

\section{Materials and Methods}

Ten male Wistar rats weighing $250-350 \mathrm{gm}$ were used. In these experiments, the guidelines of the $\mathrm{Na}$ tional Institute of Health for the care and use of laboratory animals were followed.

\section{Experimental brain contusion}

Brain contusion was produced over the lower left parietal region by mechanical impact. A fluid percussion device was designed to produce a uniform and localized unilateral contusion in one cerebral hemisphere. ${ }^{28)}$ A biphasic pressure wave with a duration of $20 \mathrm{msec}$ was delivered to the brain by impact against a vinyl chloride membrane attached to a fluid reservoir. This system produces a cortical contusion under a 4-mm burr hole through impact of a 0.5 -atm positive peak pressure and a -0.1 -atm negative peak pressure. Transient arterial hypertension, with apnea lasting about 20 seconds, always occurs immediately after the impact. 


\section{DC potential monitoring}

An Ag- $\mathrm{AgCl}$ electrode connected to a DC amplifier (Model MEZ-8201 differential preamplifier; Nihon Koden Kogyo Co. Inc., Tokyo) was used to monitor the DC potential. A silver wire $0.5 \mathrm{~mm}$ in diameter was electrolytically coated with silver chloride with a $1.5-\mathrm{V}$ battery in a dark chamber. This $\mathrm{Ag}-\mathrm{AgCl}$ electrode was embedded in agar in a plastic cap 4 $\mathrm{mm}$ in diameter. A reference electrode of $\mathrm{Ag}-\mathrm{AgCl}$ plate, $6 \mathrm{~mm}$ in diameter, was placed in the subcutaneous tissues of the back of the neck. It was confirmed in advance that a negative shift of $5-7 \mathrm{mV}$ was detectable at the time of sacrifice.

\section{Experimental protocol}

Polyethylene catheters were inserted into the femoral artery and vein under light halothanenitrous oxide anesthesia. A burr hole $4 \mathrm{~mm}$ in diameter was drilled in the lower parietal region; great care was taken to avoid damaging the dura mater. The fluid percussion device was fixed to the burr hole with cyanoacrylate, and 10 rats were given contusions as described above. The device was removed and the burr hole was closed with bone cement. Electrodes for measurement of DC potential and EEG monitoring were firmly attached with cyanoacrylate at the vertex of the skull on both sides. Only the outer table of the rat skull was drilled so as to prevent injury to the cortex and to obtain a sufficient DC potential gain. All animals were revived after the procedure and were restrained by means of a loose-fitting plaster cast placed around the lower abdomen. About 15 minutes elapsed before measurement of the DC potential and EEG recording were started. Quantitative $\left[{ }^{14} \mathrm{C}\right]$ deoxyglucose measurement was started at the lowest point of the first or second negative shift in the $\mathrm{DC}$ potential. If no negative shift in the DC potential occurred, $\left[{ }^{14} \mathrm{C}\right]$ deoxyglucose was measured after 120 minutes of observation.

\section{Measurement of physiological variables}

The mean arterial blood pressure, plasma glucose concentration, and arterial $\mathrm{pH}, \mathrm{PaO}_{2}, \mathrm{PaCO}_{2}$, and hematocrit were monitored immediately before the beginning of each 2-deoxyglucose experiment. Rectal temperature was maintained at $37^{\circ} \mathrm{C}$ with a heating lamp.

\section{Measurement of LCGU}

The procedure for measuring LCGU was described by Sokoloff et al. ${ }^{37)}$ Briefly, a pulse of 100 $\mu \mathrm{Ci} / \mathrm{kg}$ of 2-deoxy-D-[ $\left[{ }^{14} \mathrm{C}\right]$ glucose was administered via a femoral venous catheter. Arterial blood samples were rapidly drawn immediately after the pulse, for 45 minutes at timed intervals. The red cells were immediately separated by centrifugation and the plasma samples were stored on ice until analysis for glucose and $\left[{ }^{14} \mathrm{C}\right]$ deoxyglucose concentrations. At the end of the 45-minute sampling period, arterial circulation was stopped by an intravenous bolus injection of $2 \mathrm{ml}$ of saturated potassium chloride solution, and the brain was removed as rapidly as possible, frozen in isopentane, chilled to $-30^{\circ} \mathrm{C}$, sectioned, and subjected to quantitative autoradiography. LCGU was calculated from the time courses of the plasma $\left[{ }^{14} \mathrm{C}\right]$ deoxyglucose and glucose concentrations and the tissue ${ }^{14} \mathrm{C}$ concentrations, by means of the operational equation for the $\left[{ }^{14} \mathrm{C}\right]$ deoxyglucose method.

\section{Statistical analysis}

All data are expressed as the mean \pm SEM. The data were statistically analyzed by Student's two-tailed t-test. The results were considered significant at a confidence level of over $95 \%$.

\section{Results}

\section{DC potential}

The animals were divided into two groups based on DC potential changes. Group A consisted of the four rats that showed no change in the DC potential, while Group B comprised the six animals in which negative shifts in the DC potential were seen (Fig. 1). The negative shifts in the DC potential appeared 3788 minutes after the injury ( $54 \pm 6.9$ minutes), and the EEG activity was markedly depressed during the negative shifts. The frequency of negative shifts varied, the highest being every 6-7 minutes (Fig. 2).

\section{LCGU}

Autoradiographic and DC potential changes are shown together in Fig. 1. There were no significant differences in the uptake of $\left[{ }^{14} \mathrm{C}\right]$ deoxyglucose between the right and left cortices in the absence of negative shifts (Group A). In Group B, in which negative shifts in the DC potential were elicited, $\left[{ }^{14} \mathrm{C}\right]$ deoxyglucose uptake was clearly increased in the lesioned cortex relative to that in the contralateral cortex, while uptake in subcortical structures was decreased on the lesioned side.

LCGU values are shown in Table 1. In Group B, LCGU in the lesioned cortices reached $160-190 \%$ of the value obtained contralaterally $(p<0.05)$. In Group A, there were no significant differences between the right and left hemispheres and the values were generally lower than those of the lesioned cortices in Group B. 


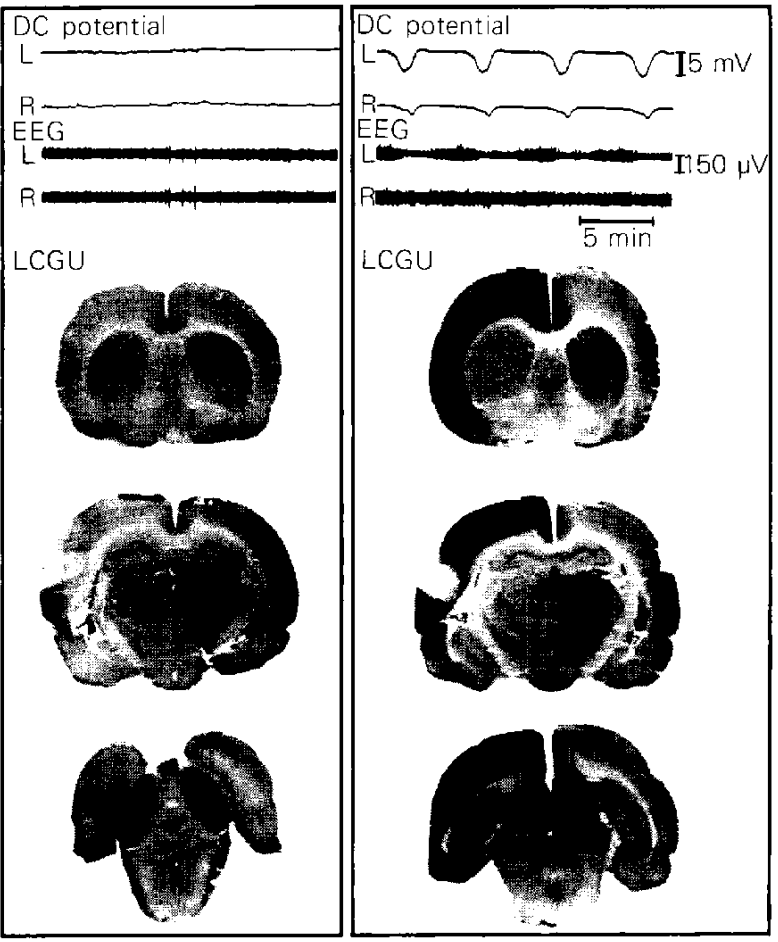

Fig. 1 Representative cases of Groups A (left) and B (right), showing simultaneous recordings of DC potential and EEG together with autoradiograms. Note that the EEG becomes markedly depressed concurrent with a negative shift in the DC potential on the lesioned side of the Group $B$ rat. Uptake of $\left[{ }^{14} \mathrm{C}\right]$ deoxyglucose is not increased in the Group A rat, while it is increased in the lesioned cortex and is decreased in the subcortical structures on the lesioned side of the Group B.

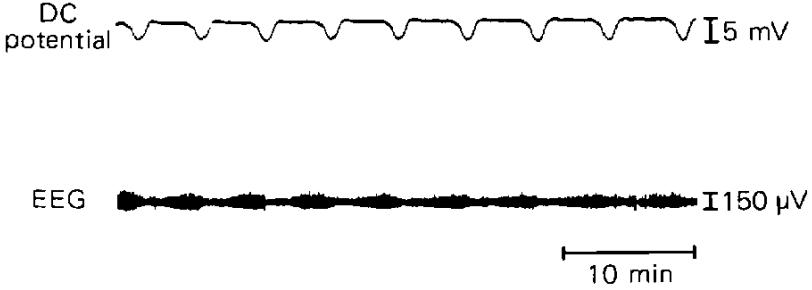

Fig. 2 Representative tracings showing frequent changes in the DC potential on the lesioned side. Negative shifts of the DC potential occurred repeatedly (every 6-7 minutes) in the lesioned cortex, concurrent with markedly depressed EEG activity.

The subcortical LCGU is also shown in Table 1. In Group B, LCGU tended to be more markedly decreased on the lesioned side than on the contralateral side but the difference was not significant. In Group A, hemispheric differences in LCGU were also insignificant.

\section{Physiological variables}

As shown in Table 2, there were no significant physiological differences between Groups A and B. No seizures, either behavioral or EEG, were noted in any animal.

\section{Discussion}

Numerous experimental models of mechanical brain injury have been developed. ${ }^{3,5-7,32,39)}$ The fluid percussion model has several advantages, as pointed out by Sullivan et $a l .{ }^{39)}$ We developed a modified fluid

Table 1 LCGU values $(\mu \mathrm{mol} / 100 \mathrm{gm} / \mathrm{min})$ in conscious rats

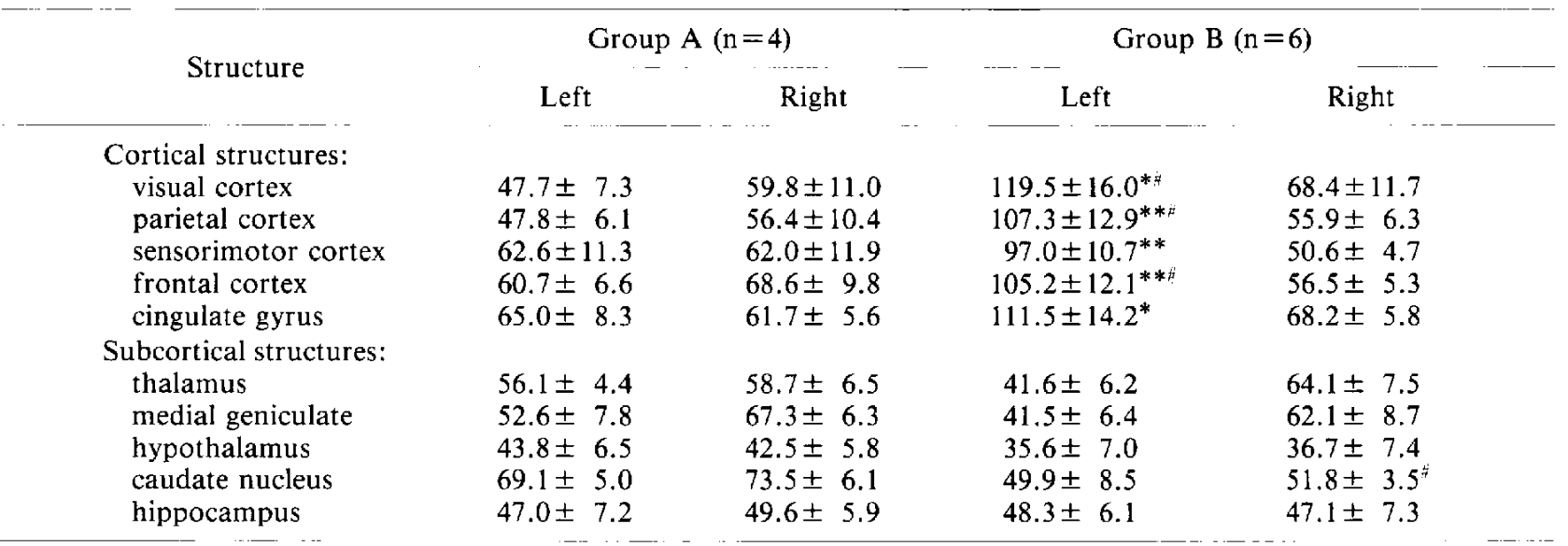

Values are means \pm SEM. ${ }^{*} \mathrm{p}<0.05$ (intragroup, left $v s$. right side), ${ }^{* *} \mathrm{p}<0.01$ (intragroup, left $v s$. right side), ${ }^{4} \mathrm{p}<0.05$ (Group B vs. Group A, same side). 
Table 2 Mean values of physiological variables

\begin{tabular}{cccccc}
\cline { 2 - 5 } & Glucose $(\mathrm{mg} / \mathrm{dl})$ & Hematocrit $(\%)$ & $\mathrm{MABP}(\mathrm{mmHg})$ & $\mathrm{PaO}_{2}(\mathrm{mmHg})$ & $\mathrm{PaCO}(\mathrm{mmHg})$ \\
\hline Group A $(\mathrm{n}=4)$ & $204 \pm 33$ & $48.8 \pm 1.9$ & $123 \pm 5.7$ & $86.1 \pm 1.8$ & $35.9 \pm 2.3$ \\
Group B $(\mathrm{n}=6)$ & $151 \pm 14$ & $47.8 \pm 2.0$ & $115 \pm 6.0$ & $88.3 \pm 2.5$ & $40.4 \pm 2.5$ \\
\hline
\end{tabular}

Values are means \pm SEM. MABP: mean arterial blood pressure.

percussion technique ${ }^{28)}$ to produce contusion in the lateral aspect of the brain rather than in the vertex ${ }^{6,39)}$ which allows comparison of differences between the right and left hemispheres.

In this study, the DC potential and EEG recordings, as well as the glucose metabolism data, were all characteristic of SD. Since the first observation of SD by Leão in $1944,{ }^{21)}$ a negative shift in the DC potential and EEG suppression have been considered the most reliable indicators of SD. ${ }^{22,23)}$ In addition, Shinohara et al $^{35)}$ noted an increase in LCGU in the hemisphere in which the DC potential negative shifts occurred, the pattern of increase (i.e., throughout the cortex) was identical to that of SD. Although a wave of EEG suppression spreading over the cortex at a speed of $3-5 \mathrm{~mm} / \mathrm{min}^{21)}$ was not demonstrated in the present study, it is highly likely that SD occurred in the Group B rats. Earlier, using an ion-sensitive microelectrode technique, we observed a marked increase in the extracellular potassium concentration $\left(\left[\mathrm{K}^{+}\right]_{0}\right)$ concurrent with the DC potential negative shift. ${ }^{18)}$

We did not anticipate the occurrence of multiple DC potential negative shifts. However, they were observed as often as 9-10 times/hour (Fig. 2), the frequency varying from rat to rat. We did not measure the DC potential just after impact; the first negative shift was observed $54 \pm 6.9$ minutes after contusion. SD may be a late phenomenon, as it appeared about 1-2 hours after brain contusion. When SD is induced by mechanical or other traumatic means, it always appears immediately after the stimulation. ${ }^{22,237}$ It is known that an increase in the $\left[\mathrm{K}^{+}\right]_{0}$ is important both in the genesis of $\mathrm{SD}^{10,11)}$ and as a consequence of SD. ${ }^{10,11,23)}\left[\mathrm{K}^{+}\right]_{0}$ must exceed a certain threshold in order to induce SD. ${ }^{10,11)}$ Takahashi et al. ${ }^{40)}$ and Hubschmann and Nathanson ${ }^{13)}$ noted a transient increase in the $\left[\mathrm{K}^{+}\right]_{0}$ either immediately or a few minutes after experimental head injury. It is not clear how $\left[\mathrm{K}^{+}\right]_{0}$ changes are brought about after 1 hour following head injury, but Nedergaard and Hansen ${ }^{29)}$ reported that, in a middle cerebral artery occlusion model, $\left[\mathrm{K}^{+}\right]_{0}$ of $40-60 \mathrm{mmol} / 1$ persisted for 2 hours at the center of the lesion and that the concentration slowly returned to the baseline level in the tissue near the ischemic area. Briefly transient and recurrent increases in $\left[\mathrm{K}^{+}\right]_{0}$ or SD occurred farther away from the lesion. Our head injury model may therefore provide useful information concerning the occurrence of SD after head injury. That is, in both our model and the middle cerebral artery occlusion model, the $\left[\mathrm{K}^{+}\right]_{0}$ is elevated due to damage of such components as vessels, neurons, and glial cells at the main point of mechanical impact.

There are problems with the $\left[{ }^{14} \mathrm{C}\right]$ deoxyglucose method of quantifying LCGU under pathological conditions. The lumped and rate constants in Sokoloff's equation ${ }^{37)}$ may be altered and the LCGU data are probably distorted at and around the impact site. However, because the physiological findings in this study were not indicative of any severe pathology, such as marked ischemia or hypoxia, we conclude that the lumped constant and glucose content do not vary greatly, especially in areas remote from the contusion. Therefore, it is likely that the enhanced uptake of $\left[{ }^{14} \mathrm{C}\right]$ deoxyglucose reflected an increase in LCGU.

Subcortical LCGU has been shown to decrease in $\mathrm{SD},{ }^{35)}$ although in our study the decrease in Group $\mathrm{B}$ was not statistically significant. Shinohara et al. ${ }^{35)}$ attributed this decrease to functional decortication due to SD. Comparison of LCGU in Groups A and B showed a statistically significant difference at the caudate nucleus, but the reason for this is unclear. It is noteworthy, however, that the SD on the lesioned side in Group B affected the subcortical structures. This in turn, may have some influence on the contralateral side.

SD is accompanied by marked changes in the extracellular microenvironment, ${ }^{4,10,14,27)}$ glucose consumption, ${ }^{8,15)}$ cortical blood flow, ${ }^{9)}$ and energy metabolites, ${ }^{24)}$ and these alterations last for several minutes. The increased LCGU in the cortex during $\mathrm{SD}$ is thought to be the consequence of increased $\left[\mathrm{K}^{+}\right]_{0}$ and activation of $\mathrm{Na}^{+}, \mathrm{K}^{+}$-ATPase. ${ }^{4,36)}$ The cortical glycogen concentration and protein synthesis remain inhibited for a longer period. ${ }^{16,17)}$ After $\mathrm{SD}$, cortical blood flow is reduced by $30 \%$ on the affected side for at least 90 minutes. ${ }^{19,20)}$ All these phenomena would result in deleterious extracellular 
changes. The delayed occurrence of SD after brain contusion has not been previously reported, and it is still unknown how SD affects the contused brain. In the event of contusion, there is likely a marginal zone in which the cells are on the verge of death. ${ }^{13}$ ) Whether they will die or recover depends on the conditions in the extracellular environment. ${ }^{13,26)}$ If SD occurs in a contused brain in which the environment has already been compromised by secondary changes, such as increased intracranial pressure and extracellular edema, further deterioration is likely, and the brain damage will spread to the marginal zone.

Although our results do not provide data regarding a possible mechanism for the occurrence of SD, they do provide information that may be useful in elucidating the pathophysiology of head injury. Although induction of SD is a much simpler matter in rats than in humans, the potential application of SD under certain circumstances in humans has been addressed. ${ }^{38)}$ It will be very interesting to discover its role in human brain contusion.

\section{Acknowledgments}

The authors thank Dr. Yashiro Hagihara, Emeritus Prof., Department of Neuropharmacology, Brain Research Institute, School of Medicine, Chiba University, for his many helpful suggestions. We also acknowledge the expert technical assistance of Mr. Koichi Sakurai and the assistance of Mrs. Hiromi Sato in the preparation of the manuscript.

This work was supported by grants no. 58480297 and no. 59480301 from the Ministry of Education, Science, and Culture of Japan.

\section{References}

1) Bruce DA, Langfitt TW, Miller JD, Schutz H, Vapalahti MP, Stanek A, Goldberg HI: Regional cerebral blood flow, intracranial pressure, and brain metabolism in comatose patients. $J$ Neurosurg 38: $131-144,1973$

2) Crockard HA, Brown FD, Trimble J, Mullan JF: Somatosensory evoked potentials, cerebral blood flow and metabolism following cerebral missile trauma in monkeys. Surg Neurol 7: 281-287, 1977

3) Crockard HA, Kang J, Ladds G: A model of focal cortical contusion in gerbils. I Neurosurg 57: 203209, 1982

4) Csiba L, Paschen W, Mies G: Regional changes in tissue $\mathrm{pH}$ and glucose content during cortical spreading depression in rat brain. Brain Res 336: $167-170,1985$

5) Denny-Brown D, Russell WR: Experimental cerebral concussion. Brain 64: 93-164, 1941

6) Dixon CE, Lyeth BG, Povlishock JT, Findling RL, Hamm RJ, Marmarou A, Young HF, Hayes RL: A fluid percussion model of experimental brain injury in the rat. $J$ Neurosurg 67: 110-119, 1987

7) Gennarelli TA, Thibault LE, Adams JH, Graham DI, Thompson CJ, Marcincin RP: Diffuse axonal injury and traumatic coma in the primate. Ann Neurol 12: $564-574,1982$

8) Gjedde A, Hansen AJ, Quistorff B: Blood-brain glucose transfer in spreading depression. I Neurochem 37: 807-812, 1981

9) Hansen AJ, Quistorff B, Gjedde A: Relationship between local changes in cortical blood flow and extracellular $\mathrm{K}^{+}$during spreading depression. Acta Physiol Scand 109: 1-6, 1980

10) Hansen $\mathrm{AJ}$, Zeuthen $\mathrm{T}$ : Extracellular ion concentrations during spreading depression and ischemia in the rat brain cortex. Acta Physiol Scand 113: 437-445, 1981

11) Harris RJ, Wieloch T, Symon L, Siesjo BK: Cerebral extracellular calcium activity in severe hypoglycemia: Relation to extracellular potassium and energy state. $J$ Cereb Blood Flow Metab 4: 187-193, 1984

12) Hayes RL, Pechura CM, Katayama $Y$, Povlishock JT, Giebel ML, Becker DP: Activation of pontine cholinergic sites implicated in unconsciousness following cerebral concussion in the cat. Science 223: 301-303, 1984

13) Hubschmann OR, Nathanson DC: The role of calcium and cellular membrane dysfunction in experimental trauma and subarachnoid hemorrhage. $J$ Neurosurg 62: 698-703, 1985

14) Kraig RP, Nicholson C: Extracellular ionic variations during spreading depression. Neuroscience 3: 10451059, 1978

15) Krivanek J: Changes of brain glycogen in the spreading EEG-depression of Leão. $J$ Neurochem 2: 337-343, 1958

16) Krivanek J: Some metabolic changes accompanying Leão's spreading cortical depression in the rat. $J$ Neurochem 6: 183-189, 1961

17) Krivanek J: Effects of spreading cortical depression on the incorporation of $\left[{ }^{14} \mathrm{C}\right]$ leucine into proteins of rat brain. $J$ Neurochem 17: 531-538, 1970

18) Kubota $M$, Nakamura $T$, Sunami $K$, Ozawa $Y$, Yamaura A, Makino $\mathrm{H}$ : Changes of local cerebral glucose utilization, DC potential, potassium in various degree of experimental head injury, in Yonemasu Y (ed): Proceedings of the 10th Conference of Japanese Society to Neurotraumatology. 1987, pp 225-231 (in Japanese)

19) Lauritzen $M$ : Long-lasting reduction of cortical blood flow of the rat brain after spreading depression with preserved autoregulation and impaired $\mathrm{CO}_{2}$ response. J Cereb Blood Flow Metab 4: 546-554, 1984

20) Lauritzen M, Jorgensen MB, Diemer NH, Gjedde A, 
Hansen AJ: Persistent oligemia of rat cerebral cortex in the wake of spreading depression. Ann Neurol 12: 469-474, 1982

21) Leão AP: Spreading depression of activity in the cerebral cortex. J Neurophysiol 7: 359-390, 1944

22) Leão AP: The slow voltage variation of cortical spreading depression of activity. Electroencephalogr Clin Neurophysiol 3: 315-321, 1951

23) Marshall WH: Spreading cortical depression of Leão. Physiol Rev 39: 239-279, 1959

24) Mayevsky A: Brain energy metabolism of the conscious rat exposed to various physiological and pathological situations. Brain Res 113: 327-338, 1976

25) Meyer JS, Kondo A, Nomura F, Sakamoto K, Teraura T: Cerebral hemodynamics and metabolism following experimental head injury. $J$ Neurosurg 32: 304-319, 1970

26) Miller JD, Becker DP: General principles and pathophysiology of head injury, in Youmans JR (ed): Neurological Surgery, vol 4. Philadelphia, WB Saunders, 1982, pp 1896-1937

27) Mutch WAC, Hansen AJ: Extracellular pH changes during spreading depression and cerebral ischemia. Mechanisms of brain $\mathrm{pH}$ regulation. $J$ Cereb Blood Flow Metab 4: 17-27, 1984

28) Nakamura $T$, Namba $H$, Sunami $K$, Kubota $M$, Ozawa Y, Yamaura A, Makino H: Study of local cerebral glucose utilization in experimental head injury. Natural course and presence of hypermetabolic state after cerebral contusion. Neurol Med Chir (Tokyo) 27: 396-403, 1987 (in Japanese)

29) Nedergaard $M$, Hansen AJ: Cortical spreading depression is elicited in focal ischemia. J Cereb Blood Flow Metab 7 [Suppl] 1: s118, 1987

30) Nelson SR, Lowry OH, Passonneau JV: Changes in energy reserves in mouse brain associated with compressive head injury, in Caveness WF, Walker AE (eds): Head Injury. Philadelphia, Lippincott, 1966, pp 444-447

31) Nilsson B, Nordstrom $\mathrm{CH}$ : Experimental head injury in the rat. Part 3: Cerebral blood flow and oxygen consumption after concussive impact acceleration. $J$ Neurosurg 47: 262-273, 1977

32) Nilsson B, Ponten U, Voigt G: Experimental head in- jury in the rat. Part 1: Mechanics, pathophysiology, and morphology in an impact acceleration trauma model. I Neurosurg 47: 241-251, 1977

33) Overgaard J, Tweed WA: Cerebral circulation after head injury. Part 4: Functional anatomy and boundary-zone flow deprivation in the first week of traumatic coma. J Neurosurg 59: 439-446, 1983

34) Shah KR, West M: The effect of concussion on cerebral uptake of 2-deoxy-d-glucose in rat. Neurosci Lett 40: 287-291, 1983

35) Shinohara M, Dollinger B, Brown G, Rapoport S, Sokoloff L: Cerebral glucose utilization: Local changes during and after recovery from spreading cortical depression. Science 203: 188-190, 1979

36) Sokoloff L: Localization of functional activity in the central nervous system by measurement of glucose utilization with radioactive deoxyglucose. $J$ Cereb Blood Flow Metab 1: 7-36, 1981

37) Sokoloff $\mathbf{L}$, Reivich $M$, Kennedy $C$, Des Rosiers $M H$, Patlak CS, Pettigrew KD, Sakurada O, Shinohara $\mathrm{M}$ : The $\left[{ }^{14} \mathrm{C}\right]$ deoxyglucose method for the measurement of local cerebral glucose utilization: Theory, procedure, and normal values in the conscious and anesthetized albino rat. $J$ Neurochem 28: 897-916, 1977

38) Sramka M, Brozek G, Bures J, Nadvornik P: Functional ablation by spreading depression. Possible use in human stereotactic neurosurgery. Appl Neurophysiol 40: 48-61, 1977/78

39) Sullivan HG, Martinez J, Becker DP, Miller JD, Griffith R, Wist AO: Fluid-percussion model of mechanical brain injury in the cat. $J$ Neurosurg 45 : 520-534, 1976

40) Takahashi H, Manaka S, Sano K: Changes in extracellular potassium concentration in cortex and brain stem during the acute phase of experimental closed head injury. $J$ Neurosurg 55: 708-717, 1981

Address reprint requests to: K. Sunami, M.D., Department of Neurological Surgery, School of Medicine, Chiba University, 1-8-1 Inohana, Chiba 280, Japan. 